\title{
EMG Sinyallerinin Kısa Zamanlı Fourier Dönüşüm Özellikleri Kullanılarak Yapay Sinir Ağları ile Sınıflandırılması
}

\author{
Ali ARI ${ }^{*}$, Furkan AYAZ2, Davut HANBAY ${ }^{3}$ \\ ${ }^{1}$ Bilgisayar Teknolojileri Bölümü, Doğanşehir Vahap Küçük MYO, Malatya Turgut Özal Üniversitesi, Malatya, Türkiye \\ ${ }^{2}$ Bilgisayar Mühendisliği Bölümü, Mühendislik Fakültesi, Bartın Üniversitesi, Bartın, Türkiye \\ ${ }^{3}$ Bilgisayar Mühendisliği Bölümü, Mühendislik Fakültesi, İnönü Üniversitesi, Malatya, Türkiye \\ ${ }^{* 1}$ ali.ari@ozal.edu.tr , ${ }^{2}$ furkan.ayaz@ bartin.edu.tr, ${ }^{3}$ davut.hanbay@inonu.edu.tr
}

(Geliş/Received: 27/03/2019;

Kabul/Accepted: 22/08/2019)

Öz: EMG sinyali kasların kasılması sırasında oluşan elektriksel aktivasyonun ölçülmesi işlemidir. EMG sinyali, kasların nöral aktivasyonu ve dinamikleri hakkında bilgi sağlamaktadır. Bu nedenle EMG sinyallerinin işlenmesi; sinir hastalıkları teşhisi, protez cihazlar ve insan makine etkileşiminde olmak üzere birçok alanda giderek daha etkin olarak kullanılmaya başlanmıştır. Özellikle EMG sinyallerinden hareket tespiti ve EMG sinyallerinin sınıflandırılması bu çalışmalar için önem teşkil etmektedir. Bu amaçla yapılan çalışmada EMG sinyallerinden hareket tespiti yapılması amaçlanmıştır. İlk olarak 6 farklı harekete ait EMG sinyalleri alınmış ve bu sinyallere Kısa Zamanlı Fourier Dönüşümü (KZFD) uygulanmış ve sinyaller Zaman-Frekans (Z-F) düzleminde gösterilmiștir. Daha sonra bu Z-F gösterimlerinden öznitelik çıkarmak amacıyla gösterimler bölütlenmis ve her bir pencereye ait istatistiksel öznitelikler, Yerel İkili Örüntü (YIÖ) değerleri ve Gri Seviye Eş oluşum Matrisi (GSEM) hesaplanarak EMG sinyaline ait öznitelikler çıkartılmıştır. Çıkarılan bu öznitelikler Yapay Sinir Ağı (YSA) ile sınıflandırılmış ve sistemin başarımı ölçülmüştür. Sistemin doğruluk başarımı ortalama \%92 olarak hesaplanmıştır.

Anahtar kelimeler: EMG Sinyalleri, Hareket Tespiti, Yapay Sinir Ağları.

\section{Classification of EMG Signals by Artificial Neural Networks Using Short-Time Fourier Transform Features}

\begin{abstract}
EMG signal is procedure that measuring electrical activation during contraction of muscles. EMG signal provides information about neural activation and dynamics of muscles. Therefore, EMG signals have been used more and more effectively in many areas like diagnosis of nervous diseases, prosthetic devices and human machine interaction. Especially, motion detection from EMG signals and classification of EMG signals are important for these studies. In this study, it is aimed to determine motion from EMG signals. Firstly, EMG signals of 6 different movements were taken and Short-Term Fourier Transform (STFT) was applied to these signals. Thus these EMG signals were transformed to Time-Frequency (T-F) domain. After than these representations used to extract features from EMG signal, statistical properties, Local Binary Pattern (LBP) values and Gray Level Co-occurrence Matrix (GLCM) were calculated from each window. These features were classified by Artificial Neural Network (ANN) and performance of system was measured. Evaluated accuracy of the system is $92 \%$.
\end{abstract}

Key words: EMG Signals, Motion Detection, Artificial Neural Network

\section{Giriș}

Elektromiyografi (EMG) işareti kasların kasılmasıyla ortaya çıkan elektriksel potansiyeldir. EMG işaretleri cilt üzerine yerleştirilen elektrotların kas liflerindeki potansiyelleri toplayarak elde edilir. EMG işaretlerinin genlikleri küçük olduğu için aktif duruma gelen kas sayısı artması ile işaretlerin okunabilirliği artmaktadır. EMG işaretleri kas hastalıkları tespitinde, protez kontrolü ve fiziksel hareketlerin sınıflandırılmasında kullanılmaktadır. Özellikle EMG sinyallerinin hareket tespiti amacıyla bilgisayar destekli sınıflandırılması ve protez kol çalışmaları son zamanlarda gözde çalışma alanları haline gelmiş ve bu alanlarda birçok çalışma yapılmıştır. Yapay zekâ metotları kullanılarak EMG sinyallerinin işlenmesi güncel çalışma alanları arasında yer almaktadır. YSA'nın öğrenme ve genelleme yeteneğinin olması yapılan çalışmalarda sıklıkla kullanılmasına sebep olmuştur. [1] nolu çalışmada Ampirik Kip Ayrışımı (AKA) yöntemi kullanılarak Amyotrofik lateral skleroz (ALS) hastalarına ve normal insanlara ait EMG sinyallerinin ayrıştırılması amaçlanmıştır. [2] nolu çalışmada EMG sinyallerinden hastalık tespiti amacıyla farklı sinir ağları yöntemleri kullanılıp sistemin otomatik olarak normal, nörojenik ve miyopatik olarak sınıflandırması amacıyla çalışma yapılmıştır. EMG sinyalinden hastalık tespiti için yapılan diğer bir çalışmada ise normal, nörojenik ve miyopatik hastalıkları tespiti için yeni bir Parçacık Sürü OptimizasyonuDestek Vektör Makinesi (PSO-DVM) modeli önerilmiş ve bu sistemin doğruluk performans değerlerini

\footnotetext{
* Sorumlu yazar: ali.ari@inonu.edu.tr Yazarların ORCID Numarası: ${ }^{1}$ 0000-0002-5071-6790, ${ }^{3}$ 0000-0003-2271-7865
} 
göstermişlerdir [3]. [4] nolu çalışmada ise protez elin işlevselliğini ve doğruluğunu arttırmak amacıyla kas kasılması, dinamik kol duruşlarını bulmaya çalışan yeni bir yöntem önermişlerdir. EMG sinyallerinden hareket tespiti için birçok yöntem ve sınıflandırıcı ile uygulamalar yapılmış ve literatüre kazandırılmıştır. [5] nolu çalışmada ise alkollü Elektroensefalografi (EEG) sinyalleri Z-F görüntülerine çevrilmiştir. Daha sonra bu görüntülerden öznitelikler çıkarılarak bu özniteliklere göre EEG sinyallerinin sınıflandırılması amaçlanmıştır. Diğer bir çalışmada ise yüzey EMG sinyali sınıflandırması için Uyarlamalı Yerel İkili Örüntü (UYIÖ) yöntemi önerilerek hareket tespiti amaçlanmıştır [6]. EMG sinyalinden hareket tespitinde sınıflandırıcı etkisi görmek amacıyla yapılan çalışmada YSA kullanılarak 3 farklı el hareketinin sınıflandırma doğruluğu hesaplanmıştır [7].

Bu çalışmada ön koldan alınan 6 farklı nesne tutmaya ait EMG sinyallerinin sınıflandırılması hedeflenmiştir. İşlem aşamasında ilk olarak alınan EMG sinyallerine Kısa Zamanlı Fourier Dönüşümü (KZFD) uygulanmış ve sinyal zaman-frekans (Z-F) düzlemine dönüştürülmüştür. Daha sonraki aşamada elde edilen Z-F görüntüleri frekans düzleminde bölütlenerek daha küçük parçalara ayrıştırılmıştır. Bu küçük alanlara istatiksel yöntemler ve doku tabanlı görüntü işleme yöntemleri olan YİÖ ve GSEM yöntemleri uygulanarak görüntülerden öznitelik çıkarımı sağlanmıştır. Elde edilen bu öznitelikler YSA'a giriş verisi olarak verilerek sistemin doğruluk başarısı maksimum $\% 93$, ortalama \%92 olarak elde edilmiştir. Yapılan çalışma şu şekilde organize edilmiştir. İkinci bölümde öznitelik çıkarımı ve sınıflandırma işlemi için kullanılan yöntemler anlatılmıştır. Üçüncü bölümde önerilen yöntem ve deneysel sonuçlar görsel ve sayısal olarak verilerek açıklamalarda bulunulmuştur. Son bölümde ise sonuçlar verilmiştir.

\section{Materyal ve Metot}

Bu bölümde bu çalışmada kullanılan yöntemlere ait bilgiler verilmiştir.

\subsection{Kısa Zamanlı Fourier Dönüşümü}

Fourier analizi sinyalin her frekans bileşenine ait enerji/güç ayrışımını verir fakat zaman bilgisi olmadığı için frekans bileşeninin hangi zaman diliminde bulunduğu hakkında bilgi vermemektedir [8], [9]. KZFD’nin arkasındaki temel mantık, Fourier dönüşümü tüm zaman dilimi boyunca uygulandığı için bu sorunu çözmek amacıyla belirli zaman diliminde hesaplanması gerektiğidir. KZFD, belirli bir $x(t)$ sinyalini belirli boyutlarda pencereler $(w(t))$ ile bölerek her bir segmente Fourier dönüşümü uygulama işlemidir. Bölünmüş sinyalin sürekli zaman alanında matematiksel denklemi Denklem (1)'de gösterilmiştir [10].

$x\left(t_{c}, t\right)=x(t) w\left(t-t_{c}\right)$

Denklem 1'de $t_{c}$ simetrik pencere fonksiyonun merkez değeridir. Bölünmüşs sinyale uygulanan Fourier dönüşümü Denklem (2)'de verilmiştir.

$x\left(t_{c}, w_{c}\right)=\int_{-\infty}^{\infty} x\left(t_{c}, t\right) e^{-j w_{c} t} d t$

Denklem 2'de $w_{c}$ pencerenin merkez frekansıdır. Spektrogram olarak bilinen enerji yoğunluğu $\left|x\left(t_{c}, w_{c}\right)\right|^{2}$ olarak tanımlanır. Bu denklem $\left(t_{c}, w_{c}\right)$ etrafındaki $x(t)$ 'nin enerjisi hesaplar. Ayrık zaman alanı için sinyal pencereleme ve KZFD işlemleri için sırasıyla Denklem (3) ve Denklem (4) kullanılmaktadır.

$x(m, n)=x(n) w(n-m)$

$x(m, l)=\sum_{n=-\infty}^{n=\infty} x(n) w(n-m) e^{\frac{-j 2 \pi l n}{m}}$

\section{2. İstatistiksel Öznitelikler}

Ortalama, standart sapma ve entropi öznitelikleri genellikle görüntünün karakteristiğini elde etmek amacıyla kullanılmıştır [11]. Ortalama, görüntü yoğunluğunun ortalama değeridir. Standart Sapma, verilerin yayılımının matematiksel olarak ifade etmek için kullanılan bir ölçüdür. Entropi, verilerin düzensizlik ölçümünde kullanılır. 


\subsection{Yerel İkili Örüntü}

YİÖ, gri seviyesinden bağımsız bir doku analiz yöntemidir. Orijinal YíÖ operatörü resmin her pikseli için bir etiket oluşturur [12]. Bu etiket, merkezi pikselin 3x3 piksel komşu pikselleri ile karş̧laştırılması sonucunda elde edilen ikili bir sayıdır. Her piksel komşuları arasındaki fark olarak etiketlenir ve $u(x)$ fonksiyonu ile iki katına çıkar [13].

$$
L B P_{P, R}\left(x_{C}\right)=u\left(x_{p}-x_{c}\right) 2^{p}, u(x)=\left\{\begin{array}{ll}
1, & y \geq 0 \\
0, & y<0
\end{array}\right\}
$$

Bu denklemde $x_{c}$ YİÖ'nün merkez pikselini, $x_{p}$ merkez pikselin komşularını, R komşunun merkez piksele olan uzaklığını ve $\mathrm{P}$ ise işleme alınacak komşularının sayısını göstermektedir. Şekil 1'de YïÖ operatörünün uygulanma yöntemi gösterilmiştir.

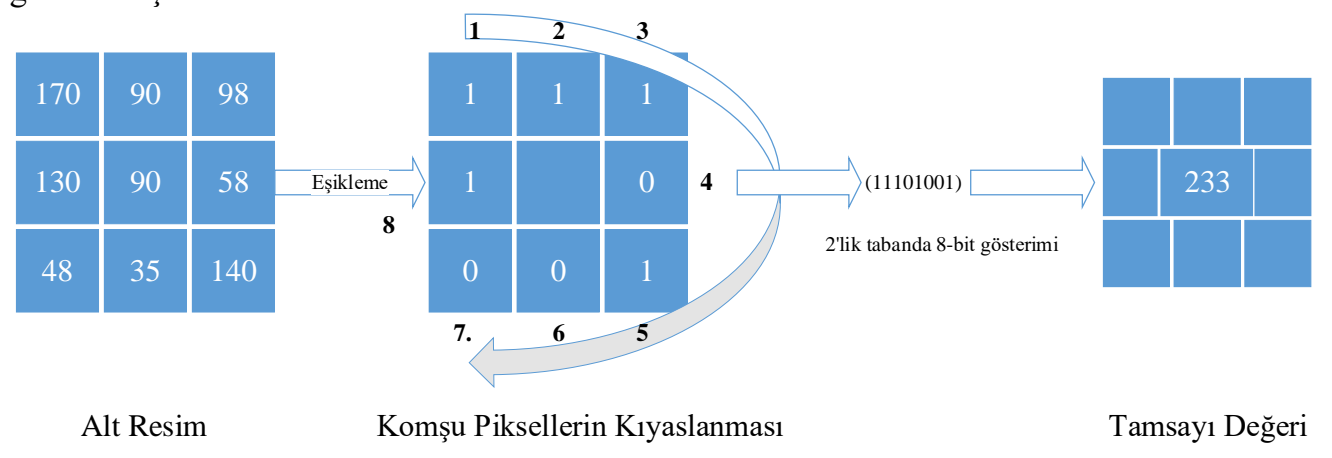

Şekil 1. YİÖ operatörünün uygulama yöntemi

Yapılan araştırmalarda, görüntülerin doku yüzeylerinin büyük bir çoğunluğu düzenli dokulardan oluştuğu gözlemlenmiştir. YïÖ operatöründe $0-1$ ve 1-0 geçişlerinin sayısı 2 ve 2'den az olan dokulara düzenli doku denmektedir. Düzenli dokulara; 00000000 ve 11111111 dokuları 0 adet geçişe, 00011000 ve 00111100 dokuları 2 adet geçişe sahip olduğu örnek olarak verilebilir [13]. Burada toplamda $P \times(P-1)+2$ düzenli doku oluşmaktadır. Düzenli olmayan piksellerin değerleri 1 tamsayı değerinde tutulduğunda, YïÖ histogramı 59 adet nokta ile temsil edilebilmektedir.

\subsection{Gri Seviye Eş Oluşum Matrisi}

GSEM, Haralick tarafından önerilmiştir ve tanımlanan dokuya ait farklı iki piksel arasındaki gri seviye farklarına dayalı bir öznitelik çıkarma yöntemidir [14]. Referans olarak birinci piksel alınırken komşu piksel olarak ikinci piksel alınır [15]. $P(I, j \mid d, 0)$, olan bu matris alt bant görüntüsündeki ve mesafe fonksiyonu arasındaki açısal ilişki ile oluşturulmuştur. Pikseller arasındaki açı d iken, açı 0 'dır. $P(I, j)$, gri seviyede ki $I$ 'dan gri seviyesinde olan j'ye geçme olasılı̆̆ını gösterir. 45 derece açı aralığı kullanılırsa tüm komşuluklar için dört matris oluşmaktadır. $P(0, d), P(45, d), P(90, d), P(135, d)$, durumlarını seçilen pikselin çevresinde 45 derecelik açıyla olacak şekilde Şekil 2'de gösterilmiştir.

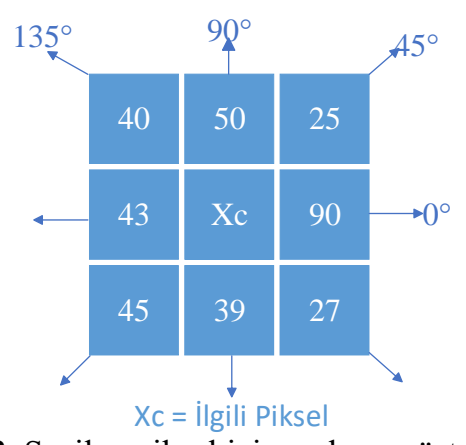

Şekil 2. Seçilen piksel için açıların gösterilmesi 
Kontrast, entropi, toplam ortalama, toplam varyans, toplam entropi, fark varyansı, fark entropisi ve korelasyon bilgi ölçüsü aşağıdaki biçimde formülize edilebilir [16].

$N g$, kullanılan gri seviyelerinin sayısıdır. $P_{x}(i), P(i, j)$ 'nin satırlarının toplanmasıyla elde edilen marjinal olasılık matrisindeki $i$ 'ninci girdidir.

$P_{x}(i)=\sum_{j=1}^{N g} P(i, j)$
$P_{y}(i)=\sum_{i=1}^{N g} P(i, j)$
$P_{x+y}(k)=\sum_{i=1}^{N g} \sum_{j=1}^{N g} P(i, j), \quad i+j=k, \quad k=2,3, \ldots, 2 N g$
$P_{x-y}(k)=\sum_{i=1}^{N g} \sum_{j=1}^{N g} P(i, j), \quad|i-j|=k, \quad k=0,1, \ldots, N g-1$

Kontrast $=\sum_{n=0}^{N g-1} n^{2}\left\{\sum_{i=1}^{N g} \sum_{j=1}^{N g} P(i, j)\right\}, \quad|i-j|=n$

Entropi $=-\sum_{i=1}^{N g} \sum_{j=1}^{N g} P(i, j) \log [P(i, j)]$

Toplam_Ortalama $=\sum_{i=2}^{2 N g} i P_{x+y}(i)$

Toplam_Varyans $=\sum_{i=2}^{2 N g}\left(i-\left[\sum_{i=2}^{2 N g} i P_{x+y}(i)\right]\right)^{2}$

Toplam_Entropi $=-\sum_{i=2}^{2 N g} P_{x+y}(i) \log \left\{P_{x+y}(i)\right\}$

Fark_Varyans $=\sum_{i=2}^{2 N g}\left(i-\left[\sum_{i=2}^{2 N g} i P_{x-y}(i)\right]\right)^{2}$

Fark_Entropi $=-\sum_{i=0}^{N g-1} P_{x-y}(i) \log \left\{P_{x-y}(i)\right\}$

Korelasyon _Bi lg $i_{-}$Ölçümü $=\frac{H X Y-H X Y 1}{\max \{H X, H Y\}}$

Denklem 13'te $H X$ ve $H Y: P_{x} P_{y}$ 'nin entropisidir.

$H X Y=-\sum_{i} \sum_{j} P(i, j) \log (P(i, j))$

$H X Y 1=-\sum_{i} \sum_{j} P(i, j) \log \left(P_{x}(i) P_{y}(j)\right)$

Enerji, Denklem (20)'deki şekilde tanımlanmıştır [17]: 
ENERJ $\dot{I}=\sum_{i} \sum_{j} P(i, j)^{2}$

\subsection{Yapay Sinir Ağları}

Birçok nörondan oluşan YSA modeli, insan beyninin biyolojik yapısı örnek alınarak tasarlanmıştır. Şekil 3'de en yaygın kullanılan YSA modeli olan ileri besleme ağının şeması gösterilmektedir. YSA'daki işlem elemanları nöronlar olarak bilinmektedir. Her bir nöron birden fazla girişe sahip olabilirken, bir çıkışa sahiplerdir. Şekil 4'de nöron yapısı gösterilmiştir. Burada $X$ giriş değerlerini, $Y$ ise çıkışı ifade etmektedir. Her bir ağırlık değeri, ağ üzerinden aktarılan sinyal ile çarpılarak hesaplanan belirli bir değere sahiptir. Bütün nöronların çıkışları aktivasyon fonksiyonu ile belirlenir. Çıkış değeri Denklem (21)'de ki formül ile hesaplanmaktadır. Burada w değerleri ağırlıkları, $\theta$ bias değerlerini ve $a($.) aktivasyon fonksiyonu ifade etmektedir. Literatürde bulunan çalışmalarda birçok aktivasyon fonksiyonu kullanılmaktadır. Genellikle aktivasyon fonksiyonu olarak tanjant sigmoid fonksiyonu kullanılmaktadır [18]. YSA genelleme yeteneğine sahip olduğu için eğitilmiş olan bir ağa sistemin bilinmediği bir girdi verildiğinde bu girdi için çıkış üretebilir [19].

$y(t+1)=a\left(\sum_{j=1}^{m} w_{i j} x_{j}(t)-\theta_{i}\right), \cdots f_{i} \Delta n e t_{i}=\sum_{j=1}^{m} w_{i j} x_{j}-\theta_{i}$

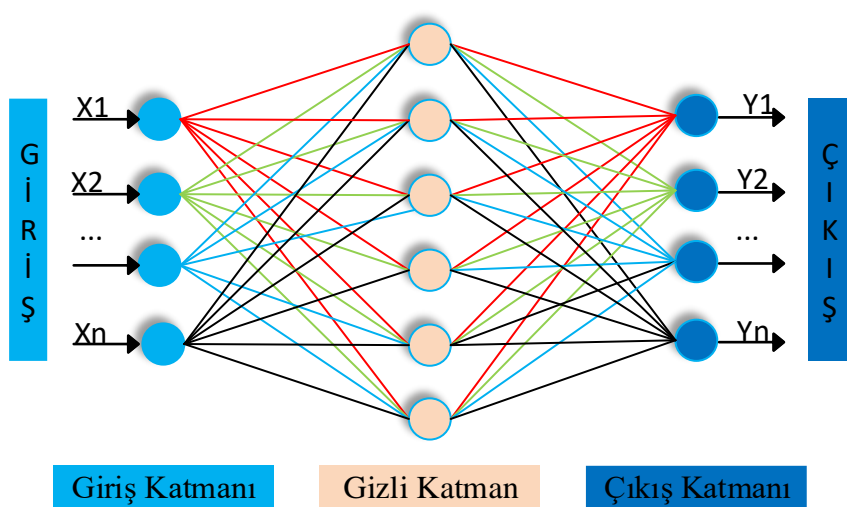

Şekil 3. YSA modelinin gösterilmesi

\section{Uygulama}

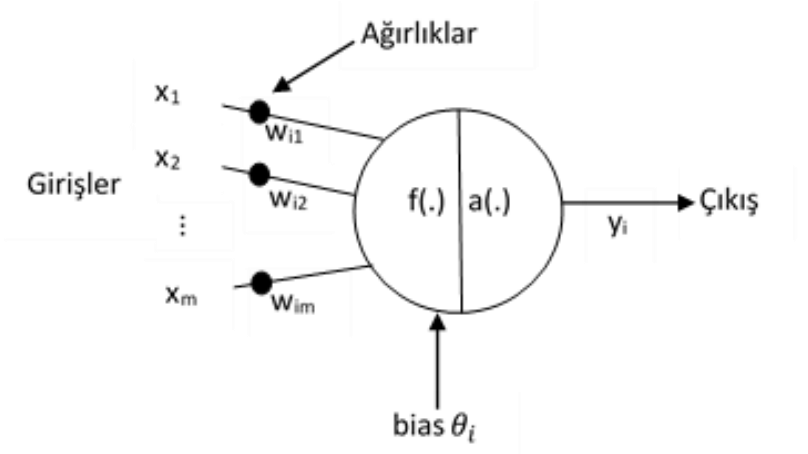

Şekil 4. Nöronun matematiksel yapısı

\section{1. Önerilen Sistem}

EMG sinyallerinin Z-F düzlemine alınmasıyla çıkarılan öznitelikler, EMG sinyalleri ile ilgili daha fazla bilgi içermektedir. Bundan dolayı EMG sinyallerine KZFD uygulanarak, EMG sinyalleri Z-F düzlemene aktarılmış ve 
Z-F gösterimleri elde edilmiştir. Elde edilen görüntüler normalize edilerek 8 bitlik gri tonlanmış gösterimlere dönüştürülmüştür. Daha sonra elde edilen $1000 * 160$ boyutundaki görüntüler, 100*160 boyutunda alt görüntülere bölütlenerek her bir parçanın sonuca olan etkisini arttırmak amaçlanmıştır. Elde edilen her bir alt görüntüye ait istatistiksel, YİÖ ve GSEM öznitelikleri çıkarılmış ve her bir alt pencereye özgün 71 adet öznitelik çıkarılmıştır. Toplama bakıldığı zaman ise bir resimde 10 adet bölüt olduğu için toplamda 710 adet öznitelik çıkarılmıştır. Veri setinde bulunan toplam hareket sayıs 1800 olduğundan dolayı tüm veri setinde toplamda $1800 * 710$ adet öznitelik çıkarılmıştır ve bu çıkarılan öznitelikler YSA ile sınıflandırılarak sistemin doğruluk başarısı hesaplanmıştır. Önerilen sistemin çalışma şeması Şekil 5'de gösterilmiştir.
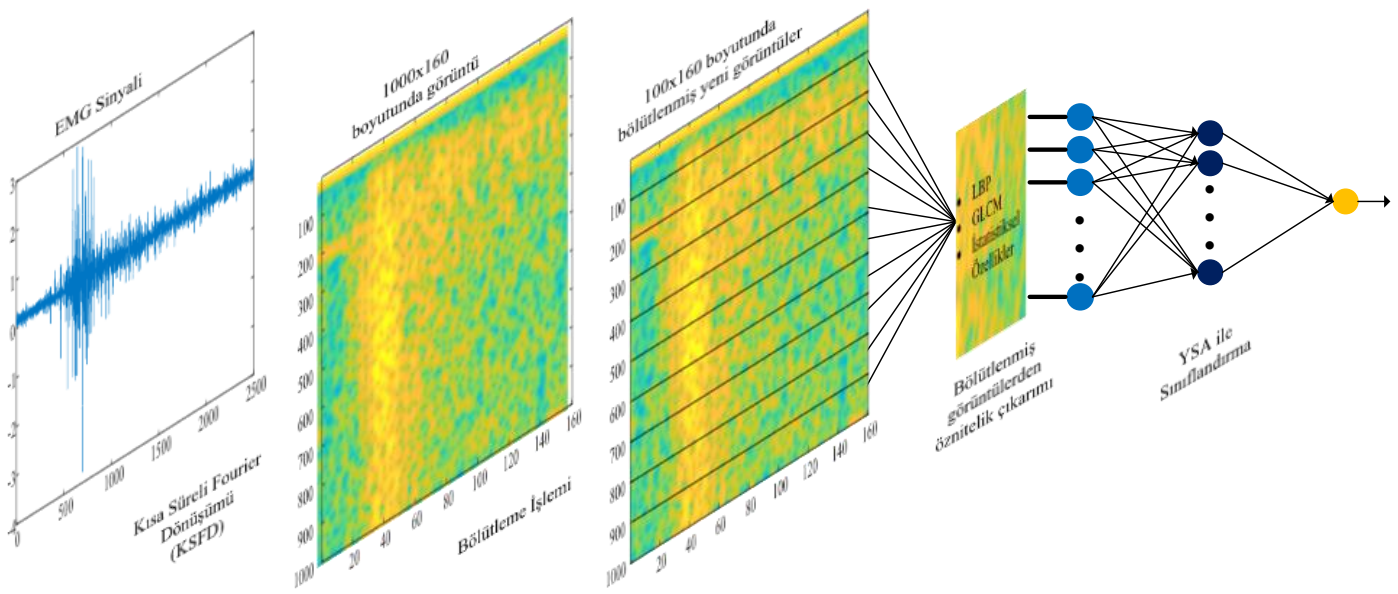

Şekil 5. Önerilen sistemin çalışma şeması

\subsection{Veri Seti}

Hazır olarak alınan veri seti, kişilerin farklı nesneleri kavramasından oluşan sinyalleri içermektedir. Ön kola takılan yüzey elektrotları ile bu kavrama hareketlerini tespit etmek amaçlanmıştır. Bir adet sağlıklı erkek bireyden yapılması istenen el hareketleri Şekil 6'da gösterilmiştir. Şekil 6'da gösterilen altı hareket; silindirik nesne tutma (A sınıfi), ağır yük tutma (B sınıfi), ince-düz nesneleri tutma (C sınıfi), avuç içine bakacak şekilde nesne kavrama (D sınıfi), küresel nesne tutma (E sınıfi) ve küçük nesne tutma (F sınıfi) hareketleri olarak belirlenmiştir. Hareketler gerçekleştirilirken hareketin deney hızı ve uygulanacak olan kuvvet kişiye bırakılarak tekrarlaması istenmiştir. Yapılması istenen nesne tutma hareketleri 3 gün artarda 5 saniyelik periyotlar ile 100 tekrar yapılmıştır. Sonuç olarak her bir harekete ait 300 adet EMG sinyali kaydedilmiştir. Alınan bu EMG sinyallerine $15 \mathrm{~Hz}$ ile $500 \mathrm{~Hz}$ arası band geçiren filtre ve $50 \mathrm{~Hz}$ çentik filtresi gürültüleri temizlemek amaciyla uygulanmıştır [20, 21].
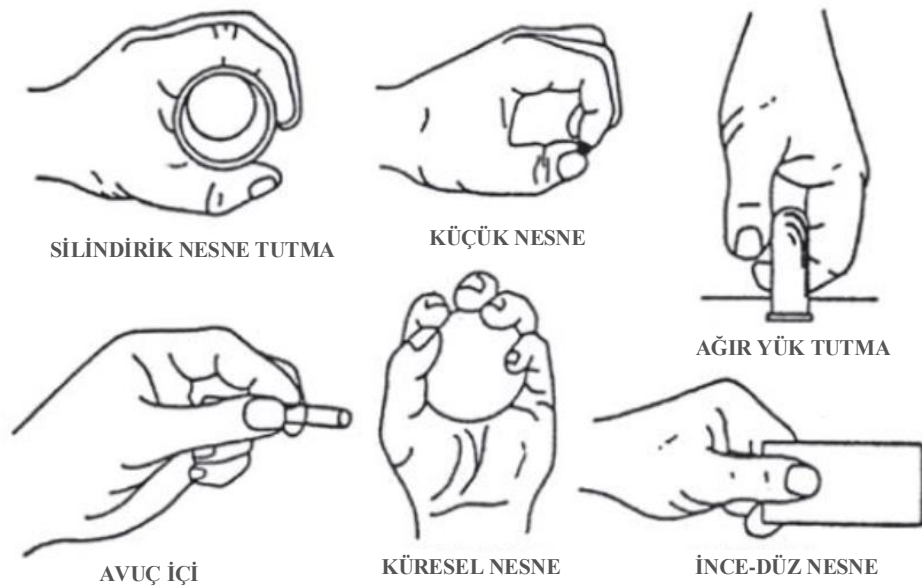

Şekil 6. Veri setinde bulunan el hareketleri 


\subsection{Deneysel Sonuçlar}

Programların koşturulduğu bilgisayar, 3.50GHz işlemci ve 8 GB bellek özelliklerine sahiptir. Program kodlamaları MATLAB 2016 ortamında yapılmıştır. Tablo 1'de sistemde kullanılan YSA modelinin mimari yapısı verilmiştir.

Tablo 1. YSA model özellikleri

\begin{tabular}{|l|l|}
\hline Katman Sayısı & 3 \\
\hline Katmanlardaki nöron sayısı & $\begin{array}{l}\text { Giriş: 710 } \\
\text { Gizli: } 30 \\
\text { Çıkış: } 6\end{array}$ \\
\hline Başlangıç ağırlıkları ve Bias Değerleri & Rastgele \\
\hline Aktivasyon Fonksiyonu & $\begin{array}{l}\text { Tanjant-sigmoid } \\
\text { Lineer }\end{array}$ \\
\hline Eğitim Parametreleri & \multicolumn{2}{|l}{} \\
\hline Öğrenme kuralı & Scaled Conjugate Gradient \\
\hline Toplam Karesel Hata & 0.0000001 \\
\hline
\end{tabular}

Yapılan çalışmada verilerin \%80'i eğitim, \%20’si ise test için kullanılmıştır. Yapılan çalışmanın sınıflandırma doğruluk başarısı maksimum \%93 olarak ortalama başarım ise \%92 olarak hesaplanmıştır. Sistemin eğitim performans grafiği Şekil 7'de, sistemin ROC eğrisi ise Şekil 8'de verilmiştir.

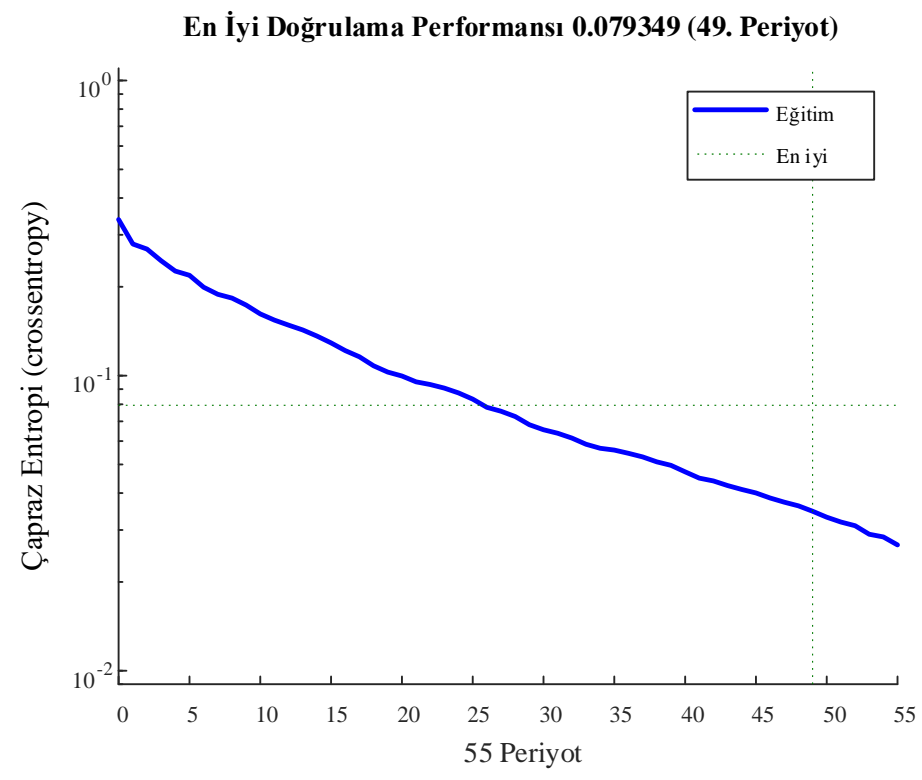

Şekil 7. Eğitim Performans1

Şekil 8'de ROC eğrisinde yer alan A, B, C, D, E, F sınıfları sırası ile silindirik nesne tutma, küçük nesne tutma, ağır yük tutma, avuç içi, küresel nesne tutma, ince- düz nesne tutma hareketlerini ifade etmektedir. AUC değeri 0.945 olarak hesaplanmıştır. 


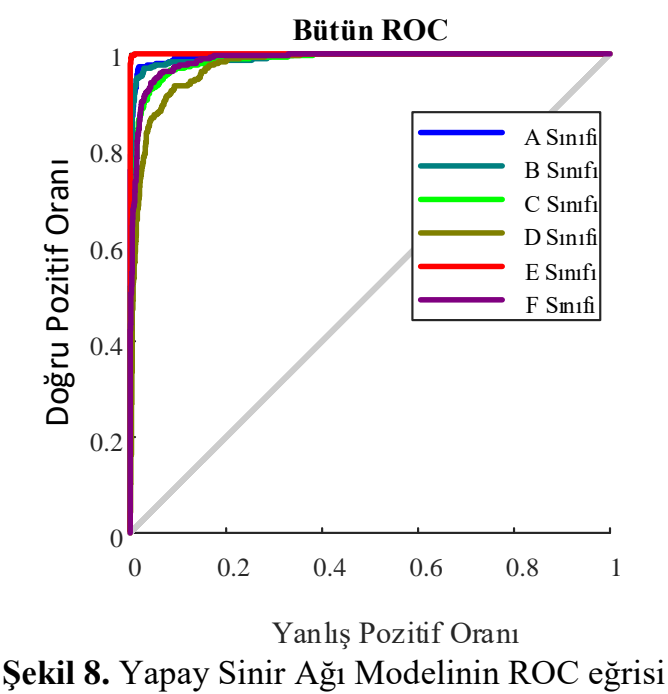

Önerilen yöntemin performans değerlendirmesinin daha iyi yapılabilmesi amacıyla, yapılan çalışmada aynı veri setini kullanan [21]'nolu çalışmanın doğruluk oranı ile kıyaslanmıştır. [21]'nolu çalışmada EMG sinyalinden hareket tespiti amacıyla ham sinyal ve ham sinyalin Değişen miktarların büyüklügünün ölçülmesinde kullanılan istatistik bir karekök ortalama (RMS) değerlerini ayrı ayrı hesaplamışlardır. Hesaplanan bu değerler Radyal Taban Fonksiyon, Sıralı Minimal Optimizasyon (SMO) ve En Küçük Kareler yöntemleri ile sınıflandırmıştır. Daha sonra sınıflandırma sonucunda çıkan doğruluk oranları kıyaslanmıştır. Başarım karşılaştırmaları Tablo 2'de sunulmuştur.

Tablo 2. Önerilen yöntemin mevcut yöntemler ile doğruluk oranlarının karşıllaştırılması

\begin{tabular}{cc}
\hline Yöntem & Ortalama Doğruluk Oranı \\
\hline Sapsanis C. [21] & $\% 80$ \\
\hline Önerilen yöntem & $\% 92$ \\
\hline
\end{tabular}

Tablo 2'de görüldüğü önerilen yöntemin doğruluk oranları karşılaştırılan yöntemden daha iyi bir sınıflandırma oranı hesaplanmıştır. Bu veriler ışığında önerilen yöntemin EMG sinyallerinin sınıflandırılmasında etkin bir şekilde kullanılabileceği görülmektedir.

\section{Sonuçlar}

Yapılan bu çalı̧̧mada EMG sinyallerinden el hareketi tespiti amacıyla sinyallin Z-F düzlemine alınarak bu gösterimlerden elde edilen öznitelikler YSA ile eğitilmiş ve sistemin başarısı ölçülmüştür. Z-F düzleminde ki gösterimlere uygulanan istatistiksel yöntemler, YIÖ ve GSEM ile sinyaller hakkından bilgiler çıkarılmaya çalışılmıştır. Bu işlem uygulanırken bütün bir sinyali değil küçük pencereler gözetilerek her bir pencerenin etkisinin maksimum olması amaçlanmıştır. Bu amaçla bölütleme işlemi yapıldıktan sonra belirtilen yöntemler ile öznitelikler çıkarılmıştır. Daha sonra hesaplanmış olan bu değerler YSA'ya giriş verisi olarak verilmiştir ve sınıflandırma başarımı ölçülmüştür. Sistemim başarım doğruluğu ortalama olarak \%92 olarak elde edilmiştir. EMG sinyallerinden hareket tespiti ve protez kol çalışmalarının işlevsel olabilmesi için sistemin doğruluk oranı ve başarımı büyük bir öneme sahiptir. Önerilen sistemin veri seti üzerinde başarılı olduğu gözlemlenmiştir. Bu nedenle elde edilen sonuçlara göre sistemin uygulamalarda kullanılabilecek bir yöntem olabileceği görülmektedir. 


\section{Kaynaklar}

[1] V. K. Mishra, V. Bajaj, A. Kumar, D. Sharma, G. K. Singh. An efficient method for analysis of EMG signals using improved empirical mode decomposition. AEU - Int. J. Electron. Commun 2017; 72: 200-209.

[2] A. Subasi. Classification of EMG signals using combined features and soft computing techniques. Appl. Soft Comput. J. 2012; 12(8): 2188-2198.

[3] A. Subasi. Classification of EMG signals using PSO optimized SVM for diagnosis of neuromuscular disorders. Comput. Biol. Med. 2013; 43(5): 576-586.

[4] R. N. Khushaba, A. Al-Timemy, S. Kodagoda, K. Nazarpour. Combined influence of forearm orientation and muscular contraction on EMG pattern recognition. Expert Syst. Appl. 2016; 61:154-161.

[5] V. Bajaj, Y. Guo, A. Sengur, S. Siuly, O. F. Alcin. A hybrid method based on time-frequency images for classification of alcohol and control EEG signals. Neural Comput. Appl., 2017; 28(12): 3717-3723.

[6] Ö. F. Ertuğrul, Y. Kaya, R. Tekin. A novel approach for SEMG signal classification with adaptive local binary patterns. Med. Biol. Eng. Comput. 2015; 1137-1146.

[7] S. M. Mane, R. A. Kambli, F. S. Kazi, N. M. Singh. Hand motion recognition from single channel surface EMG using wavelet \& artificial neural network. Procedia Comput. Sci. 2015; 49(1): 58-65.

[8] Shie Qian and Dapang Chen. Joint time-frequency analysis. IEEE Signal Process. Mag. 1999; 16(2): $52-67$.

[9] L. Cohen. Time-frequency Analysis.1995.

[10] B. S. Shaik, G. V. S. S. K. R. Naganjaneyulu, T. Chandrasheker, A. V. Narasimhadhan. A Method for QRS Delineation Based on STFT Using Adaptive Threshold. Procedia Comput. Sci. 2015; 54: 646-653.

[11] A. Ari and D. Hanbay. Detection of Brain Tumor from the MR Images by Using Hybrid Features. International Conference on Natural Science and Engineering (ICNASE'16).

[12] C. Zhao, S. Qiao, J. Sun, R. Zhao, and W. Wu. Sparsity-based shrinkage approach for practicability improvement of HLBP-based edge extraction. Nucl. Instruments Methods Phys. Res. Sect. A Accel. Spectrometers, Detect. Assoc. Equip., 2016; 825: 1-5.

[13] Y. Kaya, Ö. F. Ertugrul, R. Tekin. Two novel local binary pattern descriptors for texture analysis. Appl. Soft Comput. J., 2015; 34: 728-735.

[14] A. Şengür, Y. Guo, Y. Akbulut. Time-frequency texture descriptors of EEG signals for efficient detection of epileptic seizure. Brain Informatics. 2016; 3(2) 101-108.

[15] P. M. Arabi, G. Joshi, and N. Vamsha Deepa. Performance evaluation of GLCM and pixel intensity matrix for skin texture analysis. Perspect. Sci. 2016; 8:203-206.

[16] R. M. Haralick and K. Shanmugam. Textural Features for Image Classification. IEEE Trans. Systems, Man, and Cybernetics, 1973; 3:610-621.

[17] L. K. Soh and C. Tsatsoulis. Texture analysis of sar sea ice imagery using gray level co-occurrence matrices. IEEE Trans. Geosci. Remote Sens.,1999; 37(2):780-795.

[18] M. C. Colak, C. Colak, H. Kocatürk, S. Sağiroğlu, and I. Barutçu. Predicting coronary artery disease using different artificial neural network models. Anadolu Kardiyol. Derg. 2008; 8(4): 249-54.

[19] D. Hanbay, I. Turkoglu, and Y. Demir. Modeling switched circuits based on wavelet decomposition and neural networks. J. Franklin Inst., 2010; 347(3): 607-617.

[20] C. Sapsanis, G. Georgoulas, A. Tzes, and D. Lymberopoulos. Improving EMG based classification of basic hand movements using EMD. Proc. Annu. Int. Conf. IEEE Eng. Med. Biol. Soc. EMBS, 2013;5754-5757.

[21] C. Sapsanis. Recognition of basic hand movements using electromyography. 2013. 